\title{
Estimating impervious surfaces by linear spectral mixture analysis under semi-constrained condition
}

\author{
A Case Study in Fujin County, Heilongjiang Province, China \\ Honglei $\mathrm{Zhu}^{1,2}$, Ying $\mathrm{Li}^{1}{ }^{1}$, Bolin $\mathrm{Fu}^{1,2}$ \\ 1. Northeast Institute of Geography and Agroecology, Chinese Academy of Sciences, Changchun, Jilin, 130102 \\ 2. Graduate University of Chinese Academy of Sciences, Beijing, 100049 \\ Zhuhonglei.neigae@gmail.com
}

\begin{abstract}
Impervious surface played an important role in monitoring urban sprawl and understanding human activities. Linear spectral mixture analysis (LSMA) is commonly used to estimate impervious surface due to its simple structure and clear physical meaning. But previous researches found that LSMA seems to overestimate slightly impervious surface fraction in less developed areas (0-20\%), while underestimating it in the central business district (CBD) (over $80 \%$ ). This paper using LSMA model, under fully constrained and semi-constrained condition, developed impervious surface of Fujin town, Heilongjiang Province from the Landsat Thematic Mapper (TM) image. Accuracy evaluation was estimated between town and rural areas under the two different constraints. The results indicated that impervious surface developed by four endmembers(high albedo, low albedo, soil, and vegetation) under fully constrained and semi-constrained conditions overestimated slightly in less developed areas. Impervious surface developed by three endmembers (high albedo, soil, and vegetation) under semiconstrained condition provided a fine performance with a RMS reduced from $19.79 \%$ to $17.73 \%$.
\end{abstract}

Key words: inpervious surface; LSMA; semi-constrained condition

\section{INTRODUCTION}

Impervious surfaces refer to any surfaces that water cannot infiltrate, and are primarily associated with transportation and buildings [1]. Impervious surface has been recognized as a key indicator of environment because they are related to many environmental problems, such as water quality, stream health, and the urban heat island effect [2-3]. So accuracy impervious surface information is crucial for urban planning and environment management. Many algorithms and techniques have been proposed based on various spatial resolutions sensors of data. For medium spatial resolution data (10-100m) [4], linear spectral mixture analysis (LSMA) is commonly used to estimate impervious surface due to its simple structure and clear physical meaning [5-9]. But previous researches found that LSMA seemed to overestimate slightly impervious surface fraction in less developed areas (0-20\%), while underestimating it in the central business district (CBD) (over 80\%). This is reasonable since the fully constrained linear mixture model requires that endmember fractions are positive and sum to 1 [10]. Little research was examined in previous literature to estimate impervious surfaces under different constraints. Therefore, we try to discuss the effects of different constraints to impervious surfaces estimation and to improve the estimation accuracy.

\section{STUDY AREA}

The county of Fujin, Heilongjiang Province, was selected to implement this study. Fujin is located between $131^{\circ} 25^{\prime}$ and $133^{\circ} 26^{\prime} \mathrm{E}, 46^{\circ} 51^{\prime}$ and $47^{\circ} 31^{\prime} \mathrm{N}$ (Fig. 1). Fujin is the key grain and sugar beet base in Heilongjiang Province and one of the country's 100 major grain-producing counties in China. With the annual grain output reached 3.07 billion kilograms, Fujin was honoured as the "Chinese soybean town" and "China's northeast rice Township".

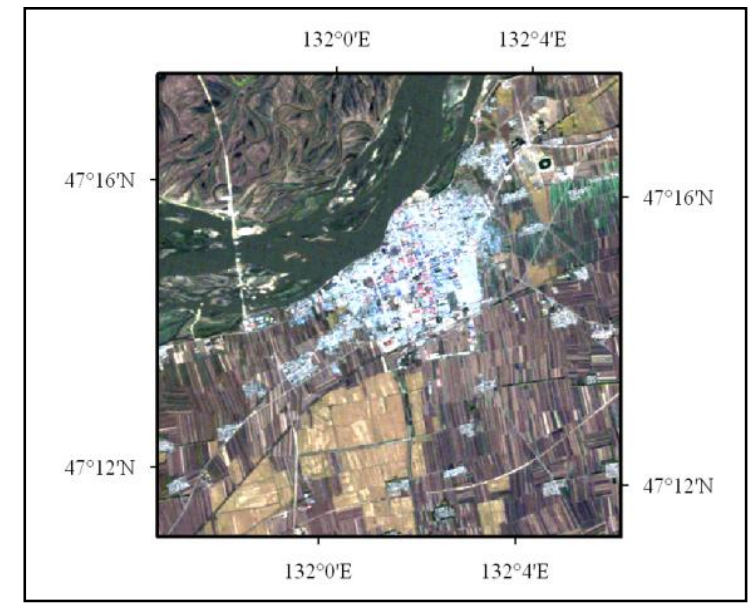

Figure 1. The study area-Fujin County, Hei Longjiang, China.

\section{DATA SOURCE}

A Landsat5 TM image, acquired on October 9, 2009 (row/path: 27/115), was chosen in this study. The digital numbers (DNs) of the TM images were converted to normalized exo-atmospheric reflectance. No atmospheric calibration was conducted for the TM images, because previous researches had demonstrated that atmospheric calibration did not have an effect on fraction images when image end members were used [11]. The study area was extracted from the reflectance image. 


\section{METHODS}

LSMA assumes that the spectrum measured by a sensor is a linear combination of the spectra of all components within the pixel. The linear mixture model is:

$$
\mathrm{R}_{\mathrm{k}}=\sum_{\mathrm{i}=1}^{\mathrm{N}} \mathrm{f}_{\mathrm{i}} \mathrm{R}_{(\mathrm{i}, \mathrm{k})}+\mathrm{e}_{\mathrm{k}}
$$

Where $R_{k}$ is the reflectance of band $k$ of a pixel; $N$ is the number of endmembers; $f_{i}$ is the proportion of endmembers $k$ within the pixel; $R_{(i, k)}$ is the spectral reflectance of endmember $\mathrm{i}$ within the pixel on band $\mathrm{k}$, and $\mathrm{e}_{\mathrm{k}}$ is the unmodeled residual for band $\mathrm{k}$ in the pixel. In this study, $\mathrm{f}_{\mathrm{i}}$ is subject to the following restrictions:

1) Fully constrained condition

$$
\sum_{\mathrm{i}=1}^{\mathrm{N}} \mathrm{f}_{\mathrm{i}}=1 \text { and } 0 \leq \mathrm{f}_{\mathrm{i}} \leq 1
$$

2) Semi-constrained condition

$$
\begin{aligned}
& \sum_{i=1}^{N} f_{i}=1 \text { and } f_{i} \geq 0 \\
& x_{i}=f_{i} / \sum_{i=1}^{N} f_{i}
\end{aligned}
$$

$\mathrm{x}_{\mathrm{i}}$ is the final proportion of endmembers $\mathrm{k}$ within the pixel and is normalized with $\mathrm{f}_{\mathrm{i}}$

The overall root mean square error (RMS) is often used to assess the fit of the model, and is computed based on errors and number of spectral bands used:

$$
\mathrm{RMS}=\sqrt{\frac{\sum_{\mathrm{i}=1}^{\mathrm{M}} \mathrm{e}_{\mathrm{k}}{ }^{2}}{\mathrm{M}}}
$$

Where $e_{k}$ is the residual for band $k, M$ is the number of spectral bands.

Endmember selection is critical for estimating impervious surfaces. Minimum noise fraction (MNF) was used to segregate and equalize the noise in the data, and to reduce the data dimensionality for target detection processing [12-13]. The resulting bands of the MNF transformed data are sorted by spatial coherence in descending order. Lower MNF bands typically have spatial structure and contain most of the information. Higher MNF bands typically have little spatial structure and contain most of the noise.

In this study, the six TM bands (1, 2, 3, 4, 5, and 7) were transformed with MNF. The first three MNF components were constructed to select four endmembers: high albedo, low albedo, soil, and vegetation. After selection of the image endmembers, a constrained least-squares solution was used to unmix the six TM reflective bands into fraction images under fully constrained and semi-constrained condition.

\section{RESULTS}

The GeoEye image of Fujin town was used for validation of impervious surface estimation results. And a random sampling method was applied to assess accuracy of impervious surfaces estimation (Fig. 2a). 107 sample plots with $5 \times 5$ pixels were generated and linked to GeoEye image.
The impervious surface objects within each sample plot were digitized on the GeoEye image (Fig. 2b). The acquisition date of the GeoEye image is April 30, 2011, which is about 6 months later than the TM image. Therefore, a careful check of each sample plot between a TM color composite and GeoEye image was conducted. Three sample plots changed a lot during the past 6 months, then they were removed from the accuracy assessment. Finally, 104 samples were used to assess the developed impervious surface image quality.

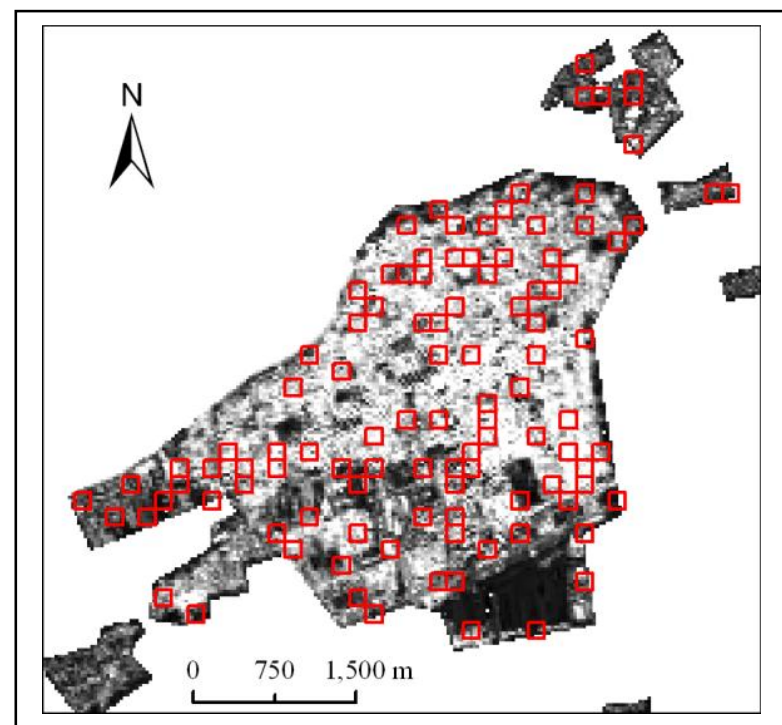

(a)

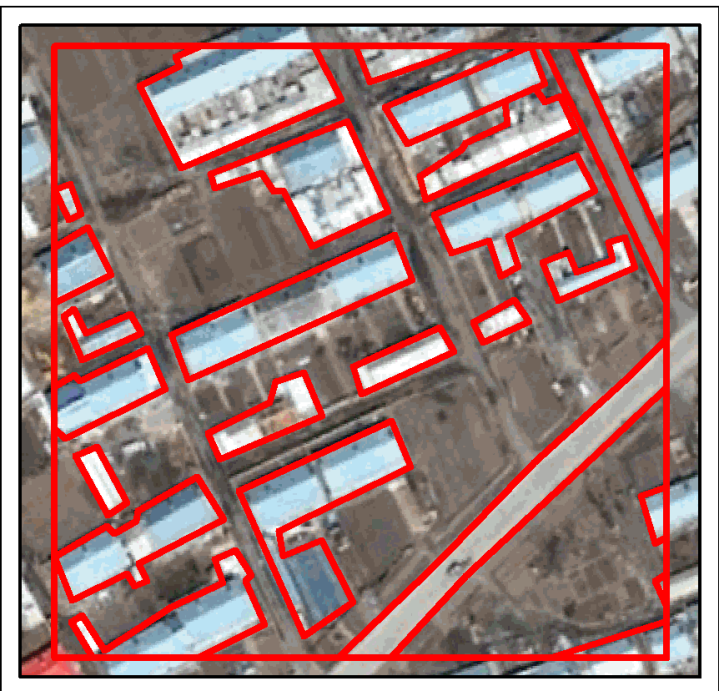

(b)

Figure 2. Strategy for collection of reference data for the accuracy assessment of impervious surface image:(a) distribution of sample plots in Fujin town; (b) the sample plot size is $5 \times 5 \mathrm{TM}$ pixels and the actual impervious surface is digitalized with Geoeye image.

Fig. 3 showed the accuracy assessment results of impervious surface. The results indicated that impervious surface developed by four endmembers under fully 
constrained and semi-constrained conditions overestimated slightly in less developed areas. Impervious surface developed by three endmembers HSV (high albedo, soil, and vegetation) provided a fine performance with a RMS of $17.73 \%$ (Table 1).
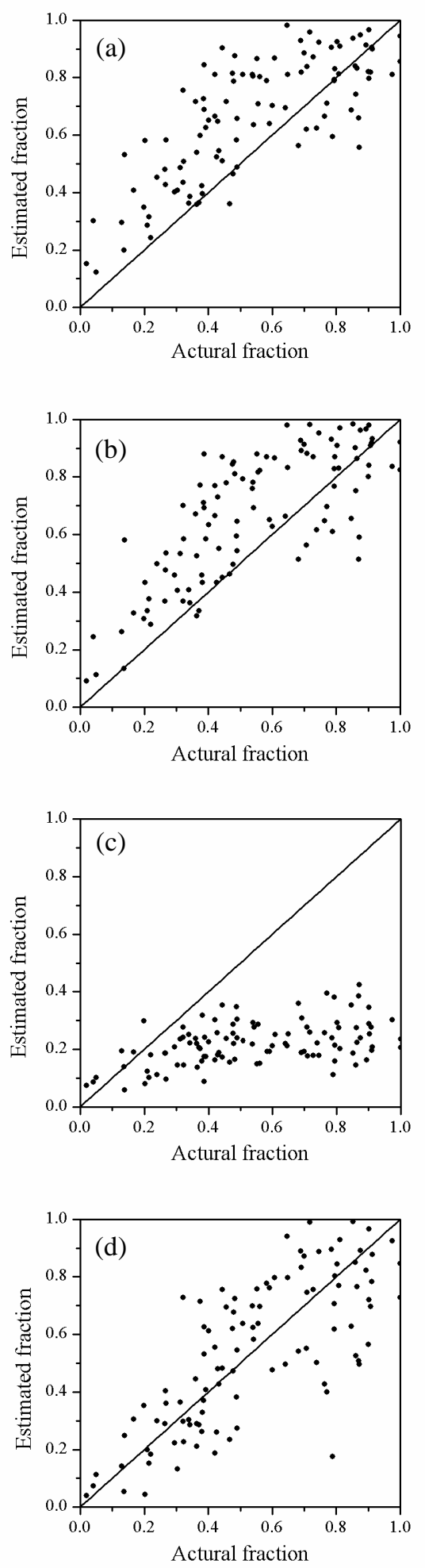

Figure 3. Results of impervious surface estimation accuracy assessment: (a) impervious surface developed by four endmembers HLSV(high albedo, low albedo, soil, and vegetation) under fully constrained condition, (b) impervious surface developed by HLSV under semi-constrained condition, (c) impervious surface developed by HSV (high albedo, soil, and vegetation) under fully constrained condition, (d) impervious surface developed by HSV under semi-constrained condition.

TABLE 1. A summary of the best constrained conditions for estimating impervious surface

\begin{tabular}{|c|c|c|}
\hline Endmembers & Constrained condition & RMS(\%) \\
\hline HLSV & Fully & $19.79 \%$ \\
\hline HLSV & Semi & $20.37 \%$ \\
\hline HSV & Fully & $39.38 \%$ \\
\hline HSV & Semi & $17.73 \%$ \\
\hline
\end{tabular}

\section{CONCLUSION}

In this paper, we developed impervious surface of Fujin from the Landsat TM image using LSMA model under fully constrained and semi-constrained condition. The results indicated that impervious surface developed by three endmembers HSV (high albedo, soil, and vegetation) under semi-constrained condition improved the estimate accuracy with a RMS reduced from $19.79 \%$ to $17.73 \%$.

The results suggest that low albedo endmember associated with water, shade and asphalt produced estimate errors in this study. Fujin urban land use and land cover classes can be modeled by the fraction of vegetation, high albedo, and soil. Low albedo fraction accounts for little in study area. Therefore, Three endmembers HSV under emi-constrained condition may provide a better result in developing impervious surface.

\section{ACKNOWLEDGMENT}

The authors wish to acknowledge the financial supports of Key Carbon Program of the Chinese Academy of Sciences (XDA05060400).

\section{REFERENCES}

[1] Ridd, M.K., "Exploring a vis (vegetation-impervious surfacesoil) model for urban ecosystem analysis through remote sensing: Comparative anatomy for cities $\uparrow$, , International Journal of Remote Sensing, vol.16, pp. 2165-2185, 1995.

[2] Lu, D., and Q. Weng, "Use of impervious surface in urban landuse classification," Remote Sensing of Environment, vol. 102, pp. 146-160, 2006.

[3] Weng, Q., D. Lu, and J. Schubring, "Estimation of land surface temperature-vegetation abundance relationship for urban heat island studies," Remote Sensing of Environment, vol. 89, pp. 467-483, 2004.

[4] Weng, Q., "Remote sensing of impervious surfaces in the urban areas: Requirements, methods, and trends," Remote Sensing of Environment, vol. 117, pp. 34-49, 2012.

[5] Lu, D., and Q. Weng, "Spectral mixture analysis of the urban landscape in indianapolis with landsat etm+ imagery," Photogrammetric Engineering and Remote Sensing, vol. 70, pp. 1053-1062, 2004. 
[6] Lu, D., and Q. Weng, "Urban classification using full spectral information of landsat etm+ imagery in marion county, indiana," Photogrammetric Engineering and Remote Sensing, vol, 71, pp. 1275-1284, 2005.

[7] Lu, D., Q. Weng, and G. Li, "Residential population estimation using a remote sensing derived impervious surface approach," International Journal of Remote Sensing, vol. 27, pp. 3553-3570, 2006.

[8] Wu, C., and A.T. Murray, "A cokriging method for estimating population density in urban areas," Computers, Environment and Urban Systems, vol. 29, pp. 558-579, 2005.

[9] $\mathrm{Wu}, \mathrm{C}$., and F. Yuan, "Seasonal sensitivity analysis of impervious surface stimation with satellite imagery," Photogrammetric Engineering and Remote Sensing, vol. 73, pp. 1393, 2007.
[10] Wu, C.S., and A.T. Murray, "Estimating impervious surface distribution by spectral mixture analysis," Remote Sensing of Environment, vol. 84, pp. 493-505, 2003.

[11] Small, C., "The landsat etm+ spectral mixing space," Remote Sensing of Environment, vol. 93, pp. 1-17, 2004.

[12] Green, A.A., M. Berman, P. Switzer, and M.D. Craig, "A transformation for ordering multispectral data in terms of image quality with implications for noise removal," Geoscience and Remote Sensing, IEEE Transactions on, vol. 26, pp. 65-74, 1988.

[13] Boardman, J. W., and Kruse, F. A., "Automated spectral analysis: a geological example using AVIRIS data, north Grapevine Mountains, Nevada: in Proceedings,” ERIM Tenth Thematic Conference on Geologic Remote Sensing, Environmental Research Institute of Michigan, Ann Arbor, MI, pp. I-407 - I-418, 1994. 